TITLE:

\title{
Laboratory evaluation of the resistance of plastics to the subterranean termite Coptotermes formosanus (Blattodea: Rhinotermitidae)
}

\section{$\operatorname{AUTHOR}(\mathrm{S})$ :}

Tsunoda, Kunio; Rosenblat, Gregory; Dohi, Koji

\section{CITATION:}

Tsunoda, Kunio ... [et al]. Laboratory evaluation of the resistance of plastics to the subterranean termite Coptotermes formosanus (Blattodea: Rhinotermitidae). International Biodeterioration \& Biodegradation 2010, 64(3): 232-237

\section{ISSUE DATE:}

2010-06

URL:

http://hdl.handle.net/2433/115103

\section{RIGHT:}

(C) 2010 Elsevier B.V.; This is not the published version. Please cite only the published version.; この論文は出版社版でありません。引用の際に は出版社版をご確認ご利用ください。 


\title{
Laboratory evaluation of the resistance of plastics to subterranean termite, Coptotermes formosanus (Blattodea: Rhinotermitidae)
}

\author{
Kunio Tsunoda ${ }^{\mathrm{a} *}$, Gregory Rosenblat ${ }^{\mathrm{b}}$, Koji Dohi ${ }^{\mathrm{b}}$ \\ ${ }^{a}$ Research Institute for Sustainable Humanosphere, Kyoto University, Uji, Kyoto 611-0011, Japan \\ ${ }^{b}$ Arkema K. K., Kyoto Technical Center, SCB\#3, Kyoto Research Park, 93 Chudoji Awatacho, \\ Shimogyou-ku, Kyoto 600-8815, Japan
}

\begin{abstract}
Since preliminary studies demonstrated unsuitability of the existing Japanese standardized methods for evaluating the termite-resistance of plastics, a new laboratory method was tested for its applicability. Assembled units, each consisting of a plastic material and a wood attachment surrounding a plastic sample were placed around a laboratory nest of Coptotermes formosanus for 6 weeks at $28 \pm 2{ }^{\circ} \mathrm{C}$ and over $80 \%$ relative humidity, and the termite attack was assessed visually. Amorphous polyamide performed best, and low density polyethylene did worst. This new laboratory method succeeded in demonstrating termite damage to materials that are susceptible under actual service conditions, although it is not applicable to evaluating insecticide-incorporated plastics. A modified JWPA Standard No.17 test method was employed to determine the minimum number of termites required to attack high density polyethylene film so that it was possible to standardize the method to compare termite resistance of non-woody materials with or without chemical treatment. It was concluded that 300 workers of Coptotermes formosanus in $12.6 \mathrm{~cm}^{2}$ foraging area, which was equivalent to the termite density (pressure) of 24 workers $\mathrm{cm}^{-2}$ foraging area, were required for termites to attack from a straight scratched surface.
\end{abstract}

Keywords: termite resistance, plastic bars, plastic films, plastic tubes (pipes), polyamide, Coptotermes formosanus

\section{Introduction}

Although plastics are extensively used under conditions with a termite hazard, there is no current information available regarding the resistance of plastics to subterranean termites. This is partly due to the lack of a standardized methodology to assess the resistance of plastic materials to subterranean termites in both the laboratory and the field. Early extensive, comprehensive studies indicated that laboratory evaluations with Australian termite species were effective for comparing the resistance of various plastics to termites (Gay and Wetherly, 1962, 1969). Those authors concluded that the susceptibility of plastics to termite attack varied considerably and that different termite species damaged the test materials to different

*Corresponding author, Tel.: +81 7743836661; fax: 81774383664

E-mail address: tsunoda@ rish.kyoto-u.ac.jp 
degrees. A later work also supported the notion that a laboratory test could be used to examine the termite-resistance of plastics (Watson et al., 1984). These Australian laboratory studies successfully reproduced the termite-susceptibility of plastics in the field test by others (Beal et al., 1973; Yamano, 1976; Beal and Bultman, 1978), possibly due to the relatively large quantity of termites (10 g of termites) used.

In previous studies we have investigated the termite-resistance of plastic films (sheets), bars and tubes (pipes) by the existing Japanese standardized methods (Rosenblat et al., 2005) and a slightly modified method (Rosenblat and Tsunoda, 2006) to determine their suitability as evaluation methods. The Japan Wood Preserving Association (1992a) standard JWPS-TW-S. 1, which was originally designed to determine the termiticidal efficacy of chemicals that are applied superficially to wood under forced-feeding conditions, seemed to be suitable for evaluating the termite-resistance of plastic bars and tubes (pipes). A single plastic specimen was placed at the center of plaster bottom of an acrylic cylindrical test container $(8 \mathrm{~cm}$ in i.d, and $5 \mathrm{~cm}$ in height) with 150 workers and 15 soldiers of Coptotermes formosanus Shiraki. A direct contact of the specimen and the plaster bottom was avoided by inserting a plastic net between them. The assembled test units were then maintained at $28 \pm 2^{\circ} \mathrm{C}$ and over $80 \%$ relative humidity for three weeks in the dark. JWPA Standard No. 17 (Japan Wood Preserving Association, 1992b), which concerns a method to evaluate the termite-resistance of non-woody materials that have been treated with termiticides or untreated, could be used to assess the resistance of plastic films (sheets) to termite penetration. A non-woody plastic film that had been previously at $60 \pm 2{ }^{\circ} \mathrm{C}$ for three months, was sandwiched by two vertically piled acrylic cylinders $(8 \mathrm{~cm}$ in i.d, and $5 \mathrm{~cm}$ in height) to determine termite penetration. A piece of red pine sapwood $(2 \times 2 \times 4 \mathrm{~cm}$ ) was buried as a food source for termites in approximately $150 \mathrm{~g}$ nest materials holding $50 \mathrm{~g}$ water in a lower cylinder, and 300 workers and 30 soldiers were introduced into the same cylinder. Upper cylinder was placed on the test film and taped together with the lower cylinder so that another red pine sapwood piece was set at the center of the film. The test unit was incubated at $28 \pm 2^{\circ} \mathrm{C}$ and over $80 \%$ relative humidity for 30 days (Rosenblat et al. 2005). A modified method of JWPA Standard No. 17 was also applied to pipe specimens with an exception of the use of wood attachments (sapwood of Cryptomeria japonica D. Don) to hold the pipe specimen and facilitate termite access to the test pipe (Rosenblat and Tsunoda, 2006).

Unfortunately, these methods did not show termite attack even to very susceptible plastics, polyethylene possibly due to an insufficient termite pressure for three weeks to 30-day tests (Rosenblat et al., 2005; Rosenblat and Tsunoda, 2006).

In current study, a new method in which test materials were directly exposed to a laboratory colony of Coptotermes formosanus was tested for its usefulness for comparing the resistance of plastics to termite attack. In addition, a minimum number of termites to cause damage to susceptible plastic material were determined when an individual plastic specimen was exposed to termites in a test container under laboratory conditions. This information seemed important to compare termite resistance of insecticide-incorporated plastic materials with the least sacrifice of termites.

\section{Materials and methods}




\section{1. Test with plastic tubes (pipes)}

Ten replicates of 6 kinds of tube (pipe) materials (outer diameter $8 \mathrm{~mm}$, length $40 \mathrm{~mm}$, wall thickness $1 \mathrm{~mm}$ ) were tested: (1) polyolefin and polyamide alloy with Shore D hardness 72 , (2) polyamide 11 with Shore D hardness 72, (3) polyamide 12 with Shore D hardness 72, (4) amorphous polyamide with Shore D hardness 83, (5) low density polyethylene (LDPE) with Shore D hardness 52, and (6) thermoplastic copolyester elastomer with Shore D hardness 62 . Plastics numbered (2), (4) and (6) have not been tested yet against any termite species.

Five of each kind of tube were artificially aged by soaking in hot water at $90^{\circ} \mathrm{C}$ for 21 days, and then sanded/scratched with medium-grade paper prior to the test. This preconditioning of specimens expected to make it easier for the termites to access the plastic tubes. The remaining five specimens of each type were tested without surface preconditioning. Since specimens in the aged-sanded/scratched group were thought to be most susceptible to termites, laboratory evaluation started with tube (pipe) specimens of this group, and followed by unaged specimens without sanding/scratching.

A plastic tube assembly is illustrated in Fig. 1. Wood attachments were made of sapwood portion of $C$. japonica which is a susceptible timber species for laboratory decay and termite used in JIS K 1571 standard tests (Japanese Industrial Standard, 2004). A 2-mm wide slit was expected to provide termites with easy access to the test materials since termites prefer such gaps for their pathways (Lenz et al. 1997). The units were buried in the soil for their full length around a laboratory nest of $C$. formosanus and kept at $28 \pm 2{ }^{\circ} \mathrm{C}$ and over $80 \%$ relative humidity for 6 weeks in the dark. . This experimental design was expected to give a greater termite pressure for each test specimen than that in a separate test container as designated in JWPA Standard No. 17 (Japan Wood Preserving Association, 1992b). The laboratory colony was originally collected from Wakayama Prefecture approximately 10 years ago and has been maintained in a concrete trough at the Research Institute for Sustainable Humanosphere of Kyoto University.

After 6 weeks of exposure to termite attack, the specimens were recovered and surface debris was cleaned off with tap water for subsequent inspection. Termite attack was assessed visually for each tube (pipe) specimen and rated according to the following scale:

10: Sound (no attack), 9: Very slight attack (very slight nibbling at the edge)*, 7: Slight attack

(slight surface excavation without holes), 4: Moderate attack (surface excavation with a couple of small holes), 1: Heavy attack (surface excavation with relatively large holes)

* Very slight nibbling at the edge actually means that no visible termite attack is noticeable on the surface.

\section{2. Test with plastic bars and films}

Five replicates of 7 kinds of bar and film (sheet) specimens with dimensions of $12 \times 60 \times 6$ (thickness) $\mathrm{mm}$ and $20 \times 40 \times$ ca 0.15 (thickness) mm, respectively, were tested. Five of the 7 kinds of test plastics were the same as those in the test with tubes, and both high density polyethylene (HDPE) with Shore D hardness 68 instead of LDPE and plasticized polyamide 11 with Shore D hardness 63 were included.

Since a preliminary test demonstrated that ageing and surface scratching of specimens did not affect the 
ease of termite attack on the plastic tubes (see Table 1), no preconditioning was applied to the bar and film specimens tested. Test bars and films were assembled with wood attachments and bound with binding copper wire (Figs. 2 and 3). The test methodology was exactly the same as that described above for the tubes. Termite attack was assessed visually for each recovered specimen and rated according to the following scale:

10: Sound (no attack), 9: Very slight attack (bar=surface/edge nibbling; film= surface/edge, $<1 / 10$ eaten)*, 7: Slight attack (bar=shallow excavation of length $<10 \mathrm{~mm}$; film=<1/5 eaten),

4: Moderate attack (bar=shallow excavation of length $>10 \mathrm{~mm}$; film $=<1 / 3$ eaten),

1: Heavy attack (bar=penetration into bar; film=>1/3 eaten)

* Very slight nibbling at the edge actually means that no visible termite attack is noticeable on the surface.

\section{3. Determination of minimum number of termites required to cause visible damage to HDPE films}

This investigation was designed to standardize a laboratory test method for evaluating termite resistance of non-woody materials, because the method to utilize a laboratory nest seemed difficult to obtain reproducible comparative results and expose chemically treated materials without sacrificing a whole nest. Preliminary trials were conducted with edge-unprotected HDPE films to select an appropriate method for the subsequent steps. A single film was used in each test condition, and exposed to 150, 300 and-500 C. formosanus workers and soldiers $10 \%$ of workers at $28 \pm 2{ }^{\circ} \mathrm{C}$ and over $80 \%$ relative humidity for 4-6 weeks in the dark. Since a modified JWPA Standard No.17 (Fig. 4) was most promising, this method using smaller chamber ( $4 \mathrm{~cm}$ in i.d) was employed to determine the minimum number of termites. The HDPE film with one face scratched or unscratched was put between two chambers which were fixed with a tape to force termites to attack from a straight film surface, and then termites were introduce into the upper chamber for 4 weeks under the same conditions mentioned above. The numbers of termites tested were 150 workers +15 soldiers, 300 workers +30 soldiers and 500 workers +50 soldiers collected from a laboratory-maintained nest of Coptotermes formosanus. Following 4-week forced feeding, each test film was visually inspected whether the termites penetrated or not. Five duplicates were tested for each condition.

\section{Results and discussion}

\section{1. Termite-resistance of plastic tubes (pipes)}

Although aged /sanded (scratched) LDPE specimens were initially expected to sustain greater termite nibbling and/or biting based on the hardness of the test tube, there was no sign of termite attack on any specimen in a previous evaluation using a separate test container with 300 workers and a single tube specimen under forced-feeding conditions (Rosenblat and Tsunoda, 2006).

The present results are shown in Table 1, where "very slight nibbling at the edge" means "no visible termite excavation with regular fluffy scratching and/or rows of fine scratching only at the edge (cut end)". 
As expected, some termite attack was easily observed on the tube specimens that were aged and scratched prior to exposure to termite attack. This supported the notion that the modified method successfully applied a greater termite pressure to test samples than the previous test method. Amorphous polyamide was the most termite-resistant material based on a complete absence of termite attack, and followed by two polyamides and polyolefin and polyamide alloy. The worst results were obtained with LDPE. Beal and Bultman (1973, 1978), who studied termite-resistance of polymeric cable coverings in the tropics, demonstrated that the duration of field exposure and the hardness of the test material significantly affect the severity of termite attack. They also reported that chlorosulfonated polyethylene gave better results than chlorinated polyethylene and cross-linked hard polyethylene after 8 years of field exposure, although laboratory evaluations using 4 species of Australian termites revealed that most of polyethylene materials were attacked with various degrees of damage among specimens of the same materials and hardness levels, and among the termite species, which included Nasutitermes exitiosus, Coptotermes lacteus and Coptotermes acinaciformis (Gay and Wetherly, 1962,1969). Polyethylene materials in the form of either a cable sheath (tube) or pipeline coating (tape) were obviously attacked by two termite species, $C$. formosanus and C. acinaciformis, in the laboratory (Watson et al., 1984). The present results with LDPE tubes were predictably similar to those in Australian trials (Watson et al., 1984), in that these materials sustained slight to moderate termite attack for a much shorter period (6 weeks) in the laboratory. Polyamide 12 generally performed well, since only the edges of test materials were very slightly nibbled by $C$. formosanus.

Table 2 shows the results of termite attack on tubes (pipes) without aging or scratching. A comparison of the results in Tables 1 and 2 clearly demonstrated that while surface smoothness and the aging process did not clearly affect termite damage of test materials, unaged and unscratched LDPE tubes tended to show less damage. When less susceptible materials were tested, termites always started attacking from the edges of specimens. This edge effect was supported by a threshold Shore D hardness of higher than 72 to prevent termite attack, whereas the threshold hardness was between 47 and 61 for test materials with a smooth surface (Watson et al., 1984).

\section{2. Termite-resistance of plastic bars and films}

The test was conducted with both bars and films (sheets) without aging and scratching, because the surface smoothness did not appear to have a significant influence on termite attack and the effect of aging was unclear in the trials with tube specimens, as shown in Tables 1 and 2. The results with bar and film (sheet) specimens without aging and scratching are shown in Table 3, and attacked film specimens are illustrated in Fig. 5.

Since the LDPE tube specimens were attacked by termites to some extent, it was considered that HDPE bar and film specimens would also sustain some termite nibbling and/or biting. HDPE film specimens were actually damaged more than or equal to LDPE tubes, and a single film specimen was completely penetrated with a rating score of 4 (moderate attack: $<1 / 3$ surface eaten), as shown in Fig. 5-C. Among the bar and film materials tested, amorphous polyamide was more termite-resistant than the other 
materials. Similar results were seen with the different forms (tube, bar or film) of plastics (Tables 1-3). However, two of the 5 replicate films of amorphous polyamide were very slightly nibbled at the edge possibly due to the effect of thickness, as indicated earlier (Gay and Wetherly, 1962, 1969). The finding that edges and cut ends are more susceptible to termite attack than a smooth straight surface (Gay and Wetherly, 1962, 1969; Watson et al., 1984) might be partly explained by the size and mechanical strength of hard biomineralized mandibles of termite (Ohmura et al., 2008).

Although termites easily gain an access to the ends of plastic materials, very slight nibbling at the ends during a limited duration of test does not always mean that termites would not attack from a straight surface for the subsequent longer period. End capping or sealing of plastic films and tubes is meaningful in the comparative termite assay only when the plastic materials are used with ends protected from termite attack. Therefore, it is often more important to demonstrate whether the plastic materials would not sustain termite attack from any part of the materials because no termite attack is thought to guarantee the resistance of test materials against termite attack.

\subsection{Minimum numbers of termites required to test termite resistance of HDPE films in the laboratory}

Any modification of the JWPS-TW-S.1 method (Japan Wood Preserving Association, 1992a) always failed in producing termite attack from the straight surface regardless of surface smoothness (scratched or unscratched) of test plastic film, although the increased number of termites more severely eroded the test film from edges as expected. However, the modified JWPA Standard No.17 (Japan Wood Preserving Association, 1992b) could afford termites with ability and opportunities to attack from the straight surface of susceptible plastics such as HDPE, only when 300 workers and 30 soldiers were introduced into the upper chamber. Penetrations were observed only with surface-scratched materials, and were easily confirmed because termites carried soil up to the upper chamber from the lower chamber through penetration holes. Termite penetrations occurred in 4 of 5 replicates within 4 days after bioassay was initiated (Fig. 6). However, no penetrations were found when 150 workers +15 soldiers or 500 workers + 50 soldiers were used. Mortality of the case with fewer termites (lower termite pressure) increased with time and reached $100 \%$ by the end of test duration. The higher termite pressure did not help them penetrate possibly due to overcrowding in a small space, although the termites ate some feeder block with the final survival rates over $50 \%$.

The present results suggested the importance of surface smoothness and the ratio between area/space for termite feeding activity and the number of termite used when a sufficient amount of food is afforded. For $C$. formosanus, the termite density 24 workers $\mathrm{cm}^{-2}$ was thought to suitable pressure for them to start attacking from the straight surface of plastic films as far as approximately $1 \mathrm{~g}$ wood is available for termites as a food and water supply source.

\section{Conclusions}

The present results have demonstrated that test samples were exposed to enough termite pressure in the 
new proposed method using a laboratory nest of $C$. formosanus to allow a comparative assessment of the termite resistance among a number of plastic materials. Therefore, this method appears to be suitable for evaluating the termite resistance of plastic materials in any form, such as bars, films (sheets) and tubes (pipes). Since the wood attachment could readily lead termites to attack the target with a 2 mm-wide slit, as illustrated in Figs. 1-3, a series of plastic specimens can be tested concurrently with the use of a laboratory termite nest or a simulated colony consisting of many termite individuals. However, only materials without insecticidal treatment can be tested by this method if samples are to be placed next to a laboratory termite nest

The nylon products tested, such as polyamide 11 , polyamide 12 and amorphous polyamide, were generally shown to be termite-resistant. As a result, these products are strongly recommended as environmentally benign alternatives to conventional polyvinyl chloride and insecticide-treated derivatives, while cost efficiency should be taken into our considerations.

Potential of laboratory evaluation to reproduce termite resistance of non-woody materials in the field was also demonstrated. Termite pressure (density) of 24 workers of $C$. formosanus $\mathrm{cm}^{-2}$ foraging area was proved to be suitable for testing non-woody materials, and the use of separate test units would allow to test both chemically treated and untreated materials..

\section{References}

Beal, R. H., Bultman, J. D., Southwell, C. R., 1973. Resistance of polymeric cable coverings to subterranean termite attack. International Biodeterioration Bulletin 9, 28-34.

Beal, R. H, Bultman, J. D., 1978. Resistance of polymeric cable coverings to subterranean termite attack after eight years of field testing in the tropics. International Biodeterioration Bulletin 14, 123-127

Gay, F. J, Wetherly, A. H. 1962. Laboratory studies of termite resistance. IV. The termite resistance of plastics. Division of Entomology (CSIRO, Melbourne, Australia) Technical. Paper No. 5, 31 pp.

Gay, F. J, Wetherly, A. H., 1969. Laboratory studies of termite resistance. V. The termite resistance of plastics. Division of Entomology (CSIRO, Melbourne, Australia) Technical. Paper No. 10, 49 pp.

Japanese Industrial Standard, 2004. JIS K 1571.Test methods for determining the effectiveness of wood preservatives and their performance requirements. Japanese Standard Association (Tokyo, Japan).

Japan Wood Preserving Association, 1992a. JWPS TW-S. 1. Laboratory test method for determining the effectiveness of termiticides applied superficially to wood and performance requirements. JWPA (Tokyo, Japan).

Japan Wood Preserving Association. 1992b. JWPA Standard No. 17. Laboratory test method for determining the protective effectiveness of termiticide-treated non-woody materials and performance requirements. JWPA (Tokyo, Japan).

Lenz, M., Schafer, B., Runko, S. Glossop. L., 1997 The concrete slab as part of a termite barrier system: Response Australian subterranean termites to cracks of different width in concrete. Sociobiology 30, 103-118. 
Ohmura, W., Suzuki, Y., Yoshimura, T., Sugiyama, J., Erwin, Imaseki, H., Ishikawa, T., Iso, H., 2008. Chemical and mechanical properties of termite mandibles. Proceedings of the $5^{\text {th }}$ Conference of the Pacific Rim Termite Research Group (March 3-4, 2008, Bali, Indonesia), 14-18.

Rosenblat, G., Hwang, W, J., Tsunoda, K., 2005. Laboratory evaluation of the termite resistance of polyamide. Proceedings of the $2^{\text {nd }}$ Conference of the Pacific Rim Termite Research Group (February 28-March 1, 2005, Bangkok, Thailand), 61-64.

Rosenblat, G., Tsunoda, K., 2006. Laboratory evaluation of the termite resistance of plastic tubes. Proceedings of the $3^{\text {rd }}$ Conference of the Pacific Rim Termite Research Group (March 6-7 2006, Guangzhou, P. R. China), 89-90.

Watson, J. A. L., Dai, Z. R., Barrett, R. A., 1984. Comparative studies on the resistance of materials to species of Coptotermes (Isoptera: Rhinotermitidae). I. The susceptibilities of various plastics to $C$. acinaciformis (Froggatt) from Australia and C. formosanus Shiraki from China. Bulletin of Entomological Research 74, 495-503.

Yamano, K., 1976. Observations on the attacked traces in PVC-sheathed cables by termites. Shiroari (Termite) 26, 2-11 (in Japanese with English abstract).

\section{Legends}

Fig. 1. Plastic tube (pipe) assembly used to evaluate termite-resistance in the laboratory colony test

Fig. 2. Plastic bar assembly used to evaluate termite-resistance in the laboratory colony test

Fig. 3. Plastic film assembly used to evaluate termite-resistance in the laboratory colony test

Fig. 4. A proposed test unit for evaluating termite resistance of non-woody materials in the laboratory

A, B: Test chambers; C: Assembled test unit with termites in the upper chamber

Fig. 5 Recovered film (sheet) specimens: (A) polyolefin and polyamide alloy was rated 7, (B) polyamide 12 was rated 9 and (C) high density polyethylene wad rated 4.

Fig. 6 Film specimens of high density polyethylene recovered from termite bioassay to determine the minimum number of termites required for penetration Dotted circle: An area exposed to termite attack; Left: A whole surface scratched; Right: A half surface scratched

Table 1. Termite attack on aged and scratched tubes (pipes)

Table 2 Termite attack on unaged and unscratched tubes (pipes)

Table 3 Termite attack on unaged and unscratched bars and films (sheets) 

2

3

4

5

6

7

8

9

10

11

12

13

14

15

16

17

18

19

20

21

22

23

24

25

26

27

28

29

30

31

32

33

34

35

36

37

38

39

40

41

42

43

44

Table 1.

Test materials

(1) Polyolefin and polyamide alloy

(2) Polyamide 11

(3) Polyamide 12

(4) Amorphous polyamide

(5) Low density polyethylene (LDPE)

(6)Thermoplastic copolyester elastomer
Visual rating of 5 replicates

Remarks

$9,9,9,9,9$

$9,9,9,9,9$

$9,9,9,9,9$

$10,10,10,10,10$

$7,7,7$

4,4

$9,9,9,9,9$
Very slight nibbling at the edge + no surface attack

Very slight nibbling at the edge + no surface attack

Very slight nibbling at the edge + no surface attack

No attack

Slight nibbling at the edge + shallow surface excavation Slight nibbling at the edge + surface excavation with holes

Very slight nibbling at the edge + no surface attack 
1

2

3

4

5

6

7

8

9

10

11

12

13

14

15

16

17

18

19

20

21

24

25

26

27

28

29

30

Table 2

\begin{tabular}{|c|c|c|}
\hline Test materials & Visual rating of 5 replicates & Remarks \\
\hline (1) Polyolefin and polyamide alloy & $9,9,9,9,9$ & $\begin{array}{l}\text { Very slight nibbling at the edge }+ \\
\text { no surface attack }\end{array}$ \\
\hline (2) Polyamide 11 & $9,9,9,9,9$ & $\begin{array}{l}\text { Very slight nibbling at the edge }+ \\
\text { no surface attack }\end{array}$ \\
\hline (3) Polyamide 12 & $9,9,9,9,9$ & $\begin{array}{l}\text { Very slight nibbling at the edge }+ \\
\text { no surface attack }\end{array}$ \\
\hline (4) Amorphous polyamide & $10,10,10,10,10$ & No attack \\
\hline \multirow[t]{3}{*}{ (5) Low density polyethylene (LDPE) } & 9 & $\begin{array}{l}\text { Very slight nibbling at the edge }+ \\
\text { no surface attack }\end{array}$ \\
\hline & 7 & $\begin{array}{l}\text { Slight nibbling at the edge }+ \\
\text { shallow surface excavation }\end{array}$ \\
\hline & $4,4,4$ & $\begin{array}{l}\text { Slight nibbling at the edge }+ \\
\text { surface excavation with holes }\end{array}$ \\
\hline (6)Thermoplastic copolyester elastomer & $9,9,9,9,9$ & $\begin{array}{l}\text { Very slight nibbling at the edge }+ \\
\text { no surface attack }\end{array}$ \\
\hline
\end{tabular}


Table 3

\begin{tabular}{|c|c|c|c|}
\hline Test materials & & Visual rating of 5 replicates & Remarks \\
\hline \multirow[t]{3}{*}{ (1) Polyolefin and polyamide alloy } & Bars & $9,9,9,9,9$ & Very slight nibbling at the edge + no surface attack \\
\hline & Films & $9,9,9,9$ & Very small part of surface eaten, expanding from nibbled edge parts \\
\hline & & 7 & Small part of surface eaten, expanding from nibbled edge parts (see Fig. 5-A) \\
\hline \multirow[t]{3}{*}{ (2) Polyamide 11} & Bars & $9,9,9,9,9$ & Very slight nibbling at the edge + no surface attack + no surface attack \\
\hline & Films & $9,9,9$ & Very slight nibbling at the edge+ no surface attack \\
\hline & & 9,9 & Very small part of surface eaten, expanding from nibbled edge parts \\
\hline \multirow[t]{3}{*}{ (3) Polyamide 12} & Bars & $9,9,9,9,9$ & Very slight nibbling at the edge + no surface attack \\
\hline & Films & 9,9 & Very slight nibbling at the edge+ no surface attack \\
\hline & & $9,9,9$ & Very small part of surface eaten, expanding from nibbled edge parts \\
\hline \multirow[t]{3}{*}{ (4) Amorphous polyamide } & Bars & $10,10,10,10,10$ & No attack \\
\hline & Films & $10,10,10$ & No attack \\
\hline & & 9,9 & Very small part of surface eaten, expanding from nibbled edge parts \\
\hline \multirow[t]{6}{*}{ (5) High density polyethylene (HDPE) } & Bars & $9,9,9,9$ & Very slight nibbling at the edge + no surface attack \\
\hline & & 4 & Slight nibbling at the edge + shallow surface excavation \\
\hline & Films & 9,9 & Very small part of surface eaten, expanding from nibbled edge parts \\
\hline & & 7,7 & Small part of surface eaten, expanding from nibbled edge parts \\
\hline & & 4 & $\begin{array}{l}\text { Slight nibbling at the edge }+ \text { small part of surface eaten forming independent holes } \\
\text { (see }\end{array}$ \\
\hline & & & Fig. $5-C)$ \\
\hline \multirow[t]{2}{*}{ (6)Thermoplastic copolyester elastomer } & Bars & $9,9,9,9,9$ & Very slight nibbling at the edge + no surface attack \\
\hline & Films & $9,9,9,9,9$ & Very small part of surface eaten, expanding from nibbled edge parts \\
\hline \multirow[t]{2}{*}{ (7) Plasticized polyamide 11} & Bars & $9,9,9,9,9$ & Very slight nibbling at the edge + no surface attack \\
\hline & Films & $9,9,9,9,9$ & Very small part of surface eaten, expanding from nibbled edge parts \\
\hline
\end{tabular}



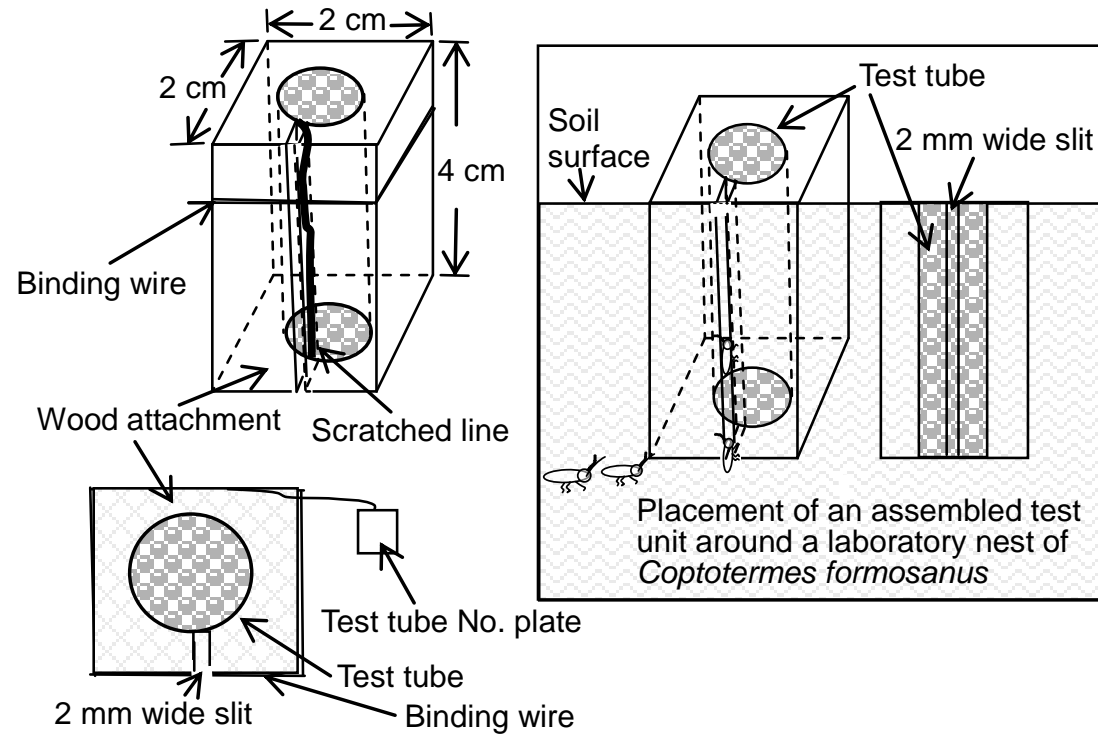

Placement of an assembled test unit around a laboratory nest of Coptotermes formosanus

$2 \mathrm{~mm}$ wide slit

Binding wire 


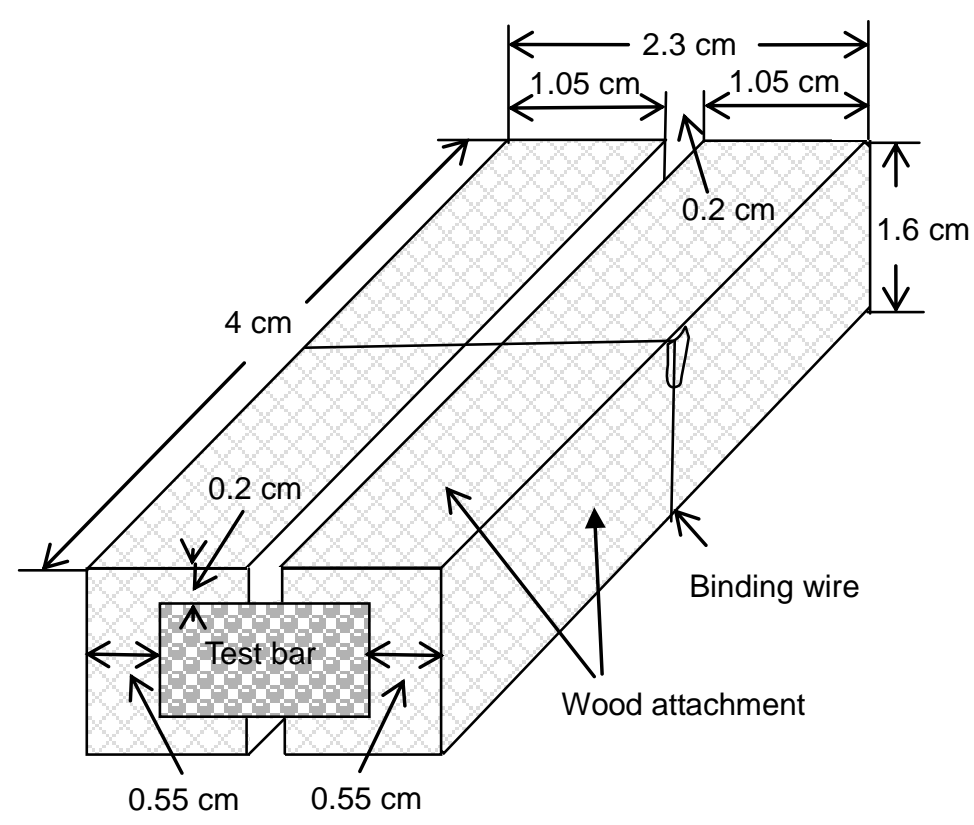




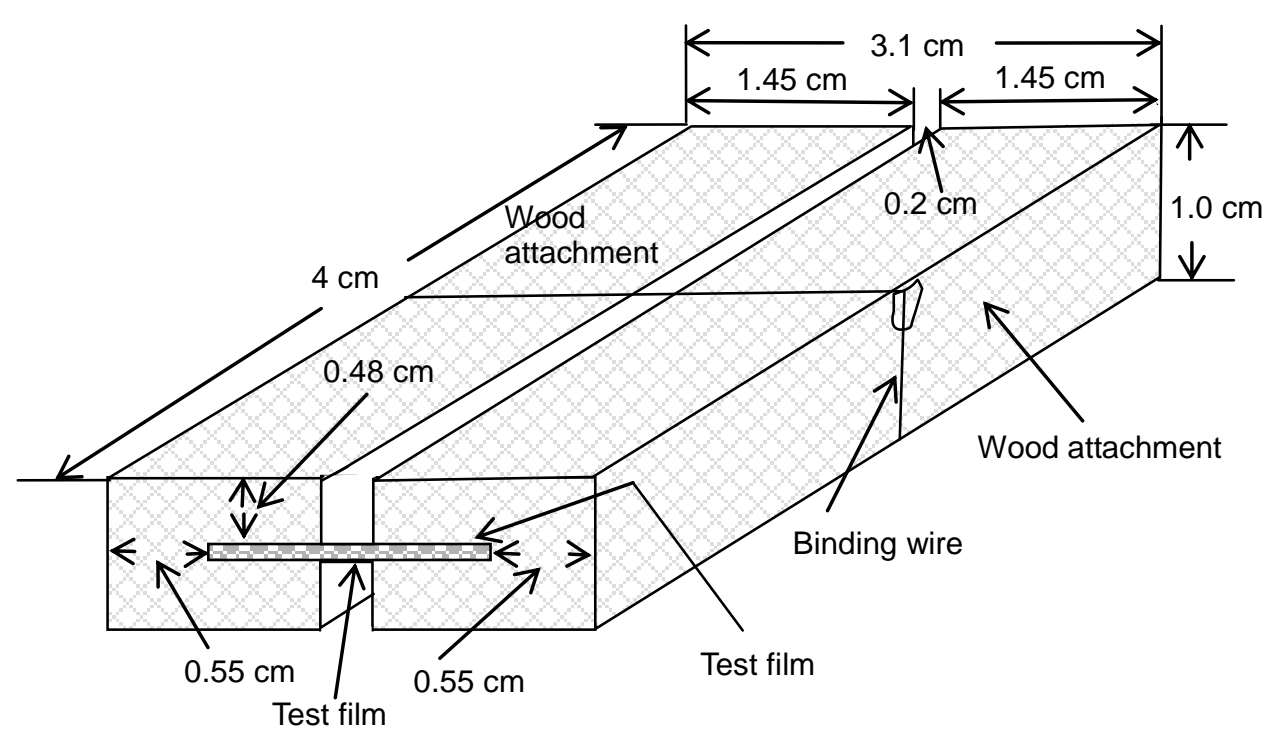




\section{9}

10

11

12

13

14

15

16

17

18

19

20

21

22

23

24

25

26

27

28

29

30

31

32

33

34

35

36

37

38

39

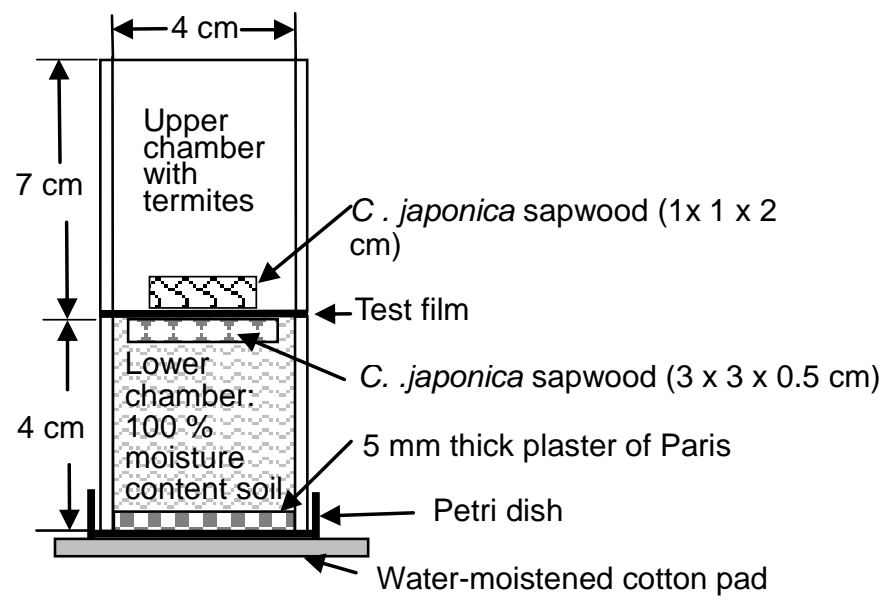

B

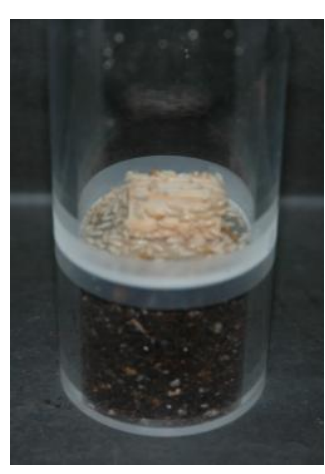

C

Fig. 4. 


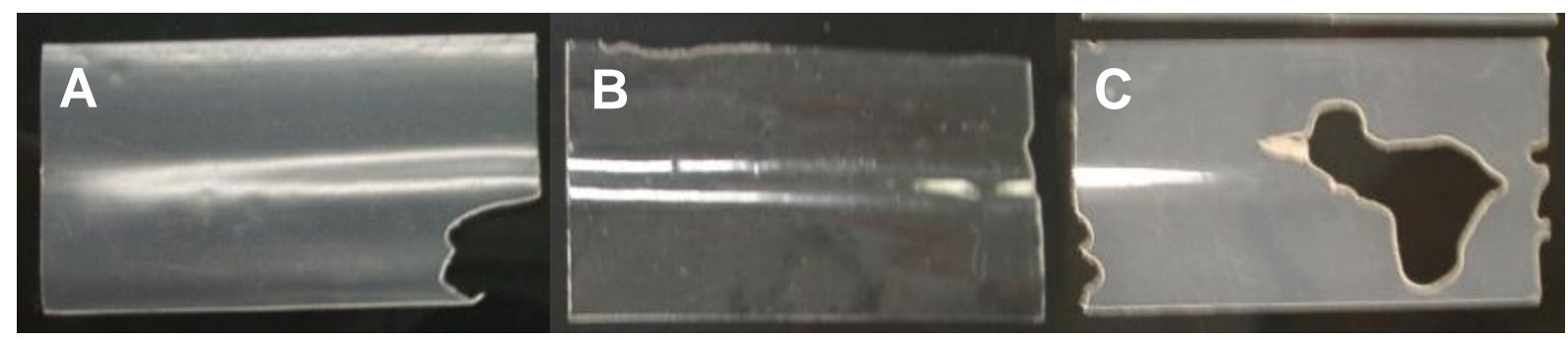

Fig. 5. 


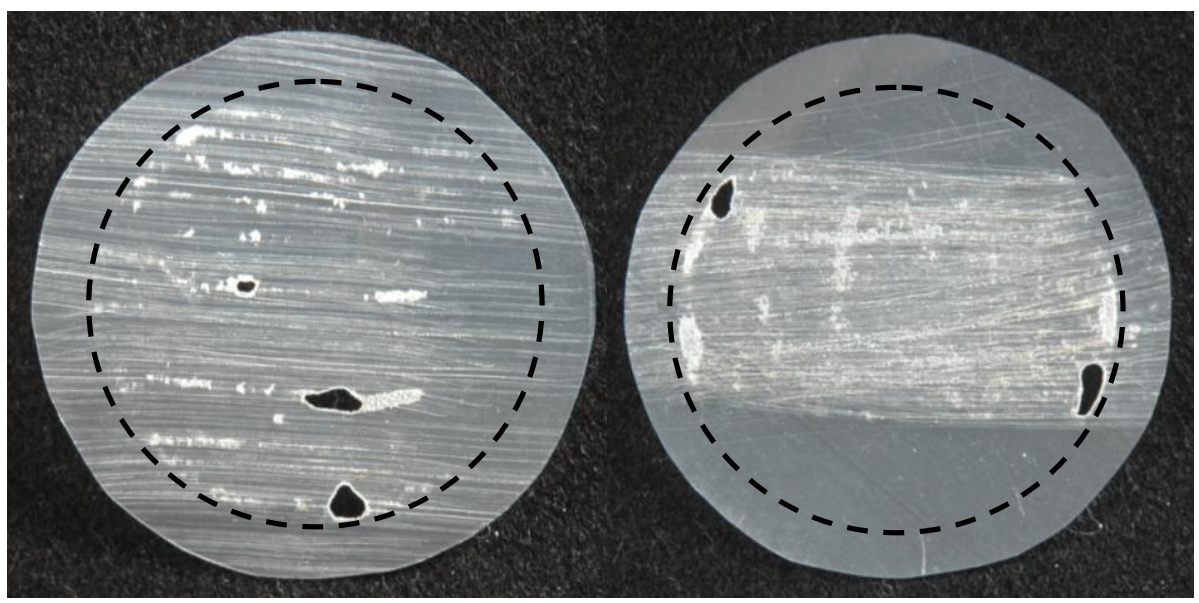

